\title{
Control of Open-Loop PWM Delta-Connected Motor-Drive Systems under One Phase Failure Condition
}

\author{
Ahmed Sayed-Ahmed ${ }^{\dagger}$ and Nabeel A. O. Demerdash* \\ $\dagger$ Standard Drives Group, Rockwell Automation, Mequon, United States \\ * Dept. of Electrical Engineering, Marquette University, Milwaukee, United States
}

\begin{abstract}
A new fault-tolerant control topology for open-loop motor-drive systems with Delta-connected stator windings is introduced in this paper. This new control topology enables the operation of a three-phase induction machine as a two-phase machine fed by a three-phase inverter upon a failure in one of the motor phases. This topology utilizes the "open-Delta" configuration to independently control the current in each of the two remaining healthy phases. This new control technique leads to the alleviation of any torque pulsations resulting from the consequences of the asymmetrical conditions associated with this class of faults.
\end{abstract}

Key Words: Delta-connected motors, Fault mitigation, Fault-tolerant motor-drive systems, Robust control, Open-loop control

\section{INTRODUCTION}

Open-loop Variable Speed Drives "VSDs" are used in a wide-spread manner in numerous industrial and commercial applications. The control of most of these drives is based on the conventional scalar constant volts-per-hertz (V/f) control, [1]. In spite of the simplicity of this approach and its associated reduced processing requirement, it can provide a smooth speed-torque control over a wide dynamic range. Although this control approach can not provide precise speed-torque control, such as in the vector-controlled closed-loop systems, the scalar (V/f) control method is adequate for most of real-world drive applications. This approach is in essence the workhorse of the ac motor-drive industry, [1]. Nevertheless, the reliability and survivability of the motor-drive system remains a significant concern especially in critical applications in which the failure of a motor-drive system may cause substantial financial loss, or even life threatening conditions. Therefore, several designs for fault-tolerant motor-drive system topologies have been proposed in [2]-[14].

To the best of these authors knowledge, earlier work in the area of fault-tolerant motor-drive systems traces back to 1980, [2]. In this work, Jahns introduced to the literature the concept of phase redundancy in fault-tolerant motor-drive systems. This technique is based on the fact that an $n$-phase motor is capable of continued operation with only " $\mathrm{n}-1$ " energized phases,

Manuscript received Apr. 4, 2010; revised Jun. 7, 2011

Recommended for publication by Associate Editor Jang-Mok Kim.

$\dagger$ Corresponding Author: asahmed@ra.rockwell.com

Tel: 001-262-512-2194, Rockwell Automation

* Dept. of Electrical Engineering, Marquette University, Milwaukee, United States provided that an $\mathrm{n}$-phase drive is capable of withstanding the stresses associated with " $n-1$ " phase operation. The scope of this research was mainly directed towards failures of semiconductor devices. This work was followed by an intensive amount of research by other investigators to enable extended operation of a motor-drive system upon the occurrence of a failure either in the driveor in the stator windings, [3]-[14]. The investigations presented in [3] introduced new winding designs that minimize or eliminate overlaps between coils from different phases. The main advantage of these designs is reducing the probability of fault propagation from one phase to another, especially for inter-turn short-circuit faults. Meanwhile, other investigations were centered on developing faulttolerant motor-drive systems vis-à-vis current sensor failure [4], switching device/ gate drive failure, and dc-bus capacitor failure [5]-[13]. To the best of these authors' knowledge, except for the work presented in [10], [11], most of these techniques are only applicable to vector-controlled motordrive systems. Moreover, most of these techniques are mainly directed towards Wye-connected machines. Fault mitigation strategies for Delta-connected machines are almost absent from the literature. Therefore, the main focus of the work presented in this paper is to introduce a robust fault-tolerant control technique that enables a Delta-connected three phase machine to run as a two-phase machine that is in an "openDelta" mode, supplied by a three-phase inverter. This topology utilizes the additional degree of freedom inherently provided in an open-Delta-connected stator. In this case, the currents in the remaining two active phases can be controlled independently. It should be highlighted that the technique presented here 
enhances the survivability of the motor-drive system in case of winding failures. It is presumed that the stator winding has an open-coil "open-turn" due to winding rupture, [13]. The origin of this type of faults is mainly caused by excessive mechanical vibrations which may produce disconnection in the U-shaped end-turn region (champ) of a coil, [15]. Another possibility is that the stator winding has an inter-turn shortcircuit fault that has been detected and the faulty phase has been isolated in an early stage (only one or two turns are shorted) using one of the techniques already documented in the literature, [16]. In this case, the circulating faulty loop current has an insignificant "ampere-turn" effect on the stator MMF, [17]. The other possibility is that the fault might start as an inter-turn short-circuit fault, which consequently causes the circulation of a high current in the faulted-coil that might end up rupturing this coil, [18]. In such applications, it is imperative to adequately design the motor windings, in replication to the work presented in [3], to be able to keep the faulted-motor in service under such mode of operation without jeopardizing the safety of the electrical installation and prohibit fault propagation to other coils in the windings. Unlike other techniques that require over-sizing/over-rating the motor and the drive, such over-sizing of the drive is not required in the presented approach. However, over-sizing the motor may be necessary if it is required that the motor develops the same power under a faulty condition as under its healthy operation. Another advantage of the present technique is that the fault mitigation controller can be activated either in the case of the normal mode of operation or the faulty mode of operation. In other words, the compensation algorithm is continuously running during healthy operation without any detectable negative impact on the system performance. However, the compensation algorithm will have its significant impact on the system performance under faulty condition in diminishing or alleviating the undesirable effects of the fault and consequently enhances the robustness of the system. In the next section, the two-phase open-Delta mode of operation will be examined. This is followed by a detailed explanation of this present control topology and its theory of operation. The controller design criteria and procedure are discussed in the next section. Then, the simulation models used in this research are presented and discussed. The results obtained from both the simulation runs and the experimental tests are presented, compared and discussed to support the theory and the analysis subject of this paper.

\section{Two Phase Operation of Wye-Connected And DELTA-CONNECTED MACHINES}

\section{A. General observations}

As detailed in [7]-[11], a two-phase mode of operation of a Wye-connected machine results in significant torque pulsations with a frequency equal to double the line frequency. This is in additional to a drag torque that opposes the useful torque developed by the machine. The currents in the two remaining active phases are dependent on each other and can not be controlled independently. In order to overcome this hurdle, the neutral point of the motor had to be accessible and was

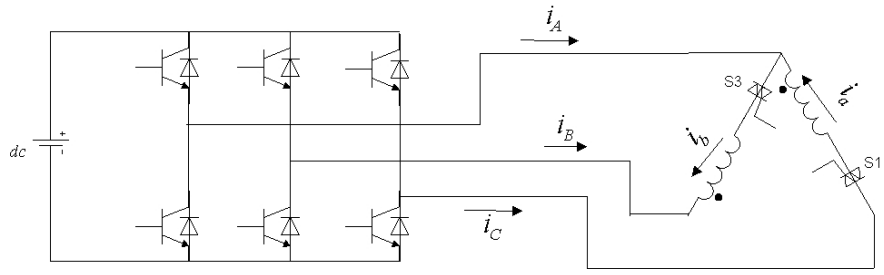

Fig. 1. Inverter fed induction motor with a Delta-connected stator winding "three-phase operation".

connected to the mid-point of the dc bus link of a drive as described in [7]-[9]. The main drawbacks of this approach are the significant increase in the dc bus capacitors' current which consequently requires an over-sizing of the dc bus capacitors. One additional approach is to connect the neutral point to an additional leg "fourth leg" in the inverter as described in [4], which consequently requires a special design for the power structure of the drive with the extra cost of the additional devices with their corresponding gate drives, and the associated control signals.

The two-phase operation of an inverter-fed induction motor with Delta-connected stator phase windings has two possible network configuration scenarios. The first scenario is that one of the power lines connecting the supply voltage to the motor is disconnected. This might be due to a blown fuse, an accidental rupture in the cable connecting the drive to the motor, a faulty switch or failure of the gate drive circuit of a switch, [4]. In this case, a motor's phase currents will not be independent of each other, hence loosing two degrees of freedom, and the machine will operate as a single phase machine. The second scenario is that one of the phases in the stator winding is disconnected as shown in Fig.1. This might be due to one of the reasons mentioned earlier in the previous section. The analysis and the topology presented in this paper are centered on providing an acceptable motor performance while the machine is running under a faulty condition that resembles the second scenario which will be referred to throughout the remaining of this paper as a "twophase open-Delta mode of operation".

\section{B. Analysis of induction motors' performance under two- phase open-Delta mode of operation}

As mentioned earlier, it is presumed that the motor windings are connected to the supply voltage. However, one of the motor phases was disconnected due to an internal fault in the windings as depicted in Fig. 1. Therefore, the relationship between the motor line currents, iA, iB, iC and phase currents, ia, ib, ic , can be expressed as follows:

$$
\begin{aligned}
& i_{a}=I_{\max } \cos (\omega t-\phi), \quad i_{b}=I_{\max } \cos (\omega t-\psi), \quad i_{c}=0 \\
& i_{A}=i_{b}-i_{a}, \quad i_{B}=-i_{b}, \quad i_{C}=i_{a} .
\end{aligned}
$$

In (1), $\phi$ and $\psi$ are arbitrary phase angles, which will be shown to be controllable through the inverter operation. In other words, examining (1) shows that, the phase currents have two degrees of freedom (DOFs), and thus the currents in these two remaining active phases can be controlled independently. The MMFs produced by the stator phase windings, presuming 
that "phase c" is the failed phase, can be expressed as follows:

$$
\begin{aligned}
& f_{a}(\theta, t)=F_{\max } \cos (\theta) \cos (\omega t-\phi) \\
& f_{b}(\theta, t)=F_{\max } \cos (\theta-120) \cos (\omega t-\psi) \\
& f_{c}(\theta, t)=0 .
\end{aligned}
$$

Therefore, the resultant stator MMF, Fs $(\theta, \mathrm{t})$, can be expressed as follows:

$$
\begin{aligned}
& F_{s}(\theta, t)=f_{a}+f_{b}+f_{c}=\left(F_{\max } / 2\right)[\cos (\theta-\omega t+\phi) \\
& +\cos (\theta-\omega t+\psi-120)]+\left(F_{\max } / 2\right)[\cos (\theta+\omega t-\phi) \\
& +\cos (\theta+\omega t-\psi-120)]
\end{aligned}
$$

Examining (3) shows that the stator MMF consists of two main components, one is a forward MMF component and the second is a backward MMF component. The magnitudes of these components can be controlled by controlling the phase shift angles, $\phi$ and $\psi$. The backward MMF component of the stator can be set to zero by controlling the stator phase currents such that $\psi-\phi=60^{\circ},[?] 7,8,9$. In this case, the resultant stator MMF can be shown to be expressed as follows:

$$
F_{s}(\theta, t)=f_{a}+f_{b}+f_{c}=\frac{\sqrt{3}}{2} F_{\max } \sin (\theta-\omega t)
$$

Inspection of (4) shows that the magnitude of the remaining two active phase currents should be increased by a factor of $\sqrt{3}$ in order to maintain the same amplitude of the stator MMF ((3/2) Fmax) in the airgap. In other words, the output power will be only limited in this case to $1 / \sqrt{3}$ p.u. of the rated power if the motor phase currents in the remaining two active phases are limited to the rated value. This fact was also shown in [7][9] for Wye-connected machines. Eliminating the backward component of the stator MMF has two advantages. The first one is to increase the net developed torque produced by the machine. This is achieved by diminishing the drag torque resulting from the interaction between the backward MMF (CW) component of the stator and the backward MMF (CW) component of the rotor. The second advantage is to eliminate or alleviate the torque ripples resulting from the interaction between the forward MMF (CCW) component of the stator and the backward MMF (CW) component of the rotor, and the interaction between the backward MMF (CW) component of the stator and the forward MMF (CCW) component of the rotor.

\section{DesCription OF THE INTROdUCED CONTROL} TOPOLOGY

\section{A. Basic concepts}

The theoretical basics of the control strategy introduced here are applicable to any ac motor with Delta-connected stator windings. It is conceived in such a manner as to enhance the survivability of the motor-drive system, when a winding failure (open-coil/open turns fault) occurs in one of its phases as explained earlier. This strategy does not require any special fault activation algorithm that alters the original motor-drive operating algorithm. Hence, this approach avoids system transients, which may occur upon the detection of the fault at the instant of transfer between two different control algorithms. The compensation algorithm introduced here is intended to be activated immediately after the startup of a machine. Hence, it enhances the robustness of the existing open-loop scalar constant (V/f) control. Under healthy condition, the conventional constant (V/f) control schemes are normally operated in addition to (in parallel with) the compensation control algorithm. In this case, the effect of the compensation algorithm on the overall control performance is negligible, as will be shown below. Upon disconnecting one of the motor phases according to the second scenario described earlier, the output of the compensation algorithm will become dominant in order to diminish the backward MMF component of the stator due to the unbalance introduced by the faulty condition.

This new control strategy is based on the idea of multiple reference frames explored before in previous publications [19], [20] with regard to other applications such as controlling the output current of an Uninterrupted Power Supply "UPS". This is in order to provide a balanced set of currents even in the case of existing unbalanced loads. In such a case, unbalanced operation of UPS units results in high current ripples in their dc-link capacitors and inductors, which may produce additional thermal stresses and significant reduction in such capacitor and inductor life-times. This is also the case for dc-link capacitors in drive systems, especially for the case of a two-phase mode of operation of a three-phase ac motor. In a motor-drive with a Delta-connected motor application, when one of the motor phases is disconnected, the currents flowing in the remaining active phase windings are highly unbalanced, and the resulting stator MMF is dependent on the phase shift between the currents flowing through the other two healthy phases as described before, see (3). Therefore, the compensation algorithm mainly controls the motor line currents to produce a near perfect rotating stator MMF only in the forward direction. This is achieved by forcing the stator backward MMF component to near zero through forcing the backward component of the stator current space-vector to zero.

Consider a healthy machine, the stator MMF of which can be expressed in space-vector notation as follows [21]:

$$
\vec{F}_{s}=\frac{3}{2} N K_{w} \vec{i}_{s}
$$

Where, $\vec{i}_{s}$ is the space-vector of the stator current and it can be expressed in terms of the three-phase currents and the complex operator $a=1 \angle 120 \mathrm{e}$ as follows [21]:

$$
\overrightarrow{i_{s}}=i_{a}+a i_{b}+a^{2} i_{c}=I_{s} e^{j(\omega t-\theta)}
$$

where, $I_{s}$, is the amplitude (peak) of the balanced stator phase currents. Now, when one of the phases is disconnected, the stator current space-vector can be decomposed into a forward component and a backward component as follows:

$$
\vec{i}_{s}=\vec{i}_{s f}+\vec{i}_{s b}
$$

Hence, the stator MMF space-vector, $\vec{F}_{s}$, that corresponds to the current space-vector components can be expressed as follows:

$$
\vec{F}_{s}=\frac{3}{2} N K_{w} \vec{i}_{s f}+\frac{3}{2} N K_{w} \vec{i}_{s b}
$$




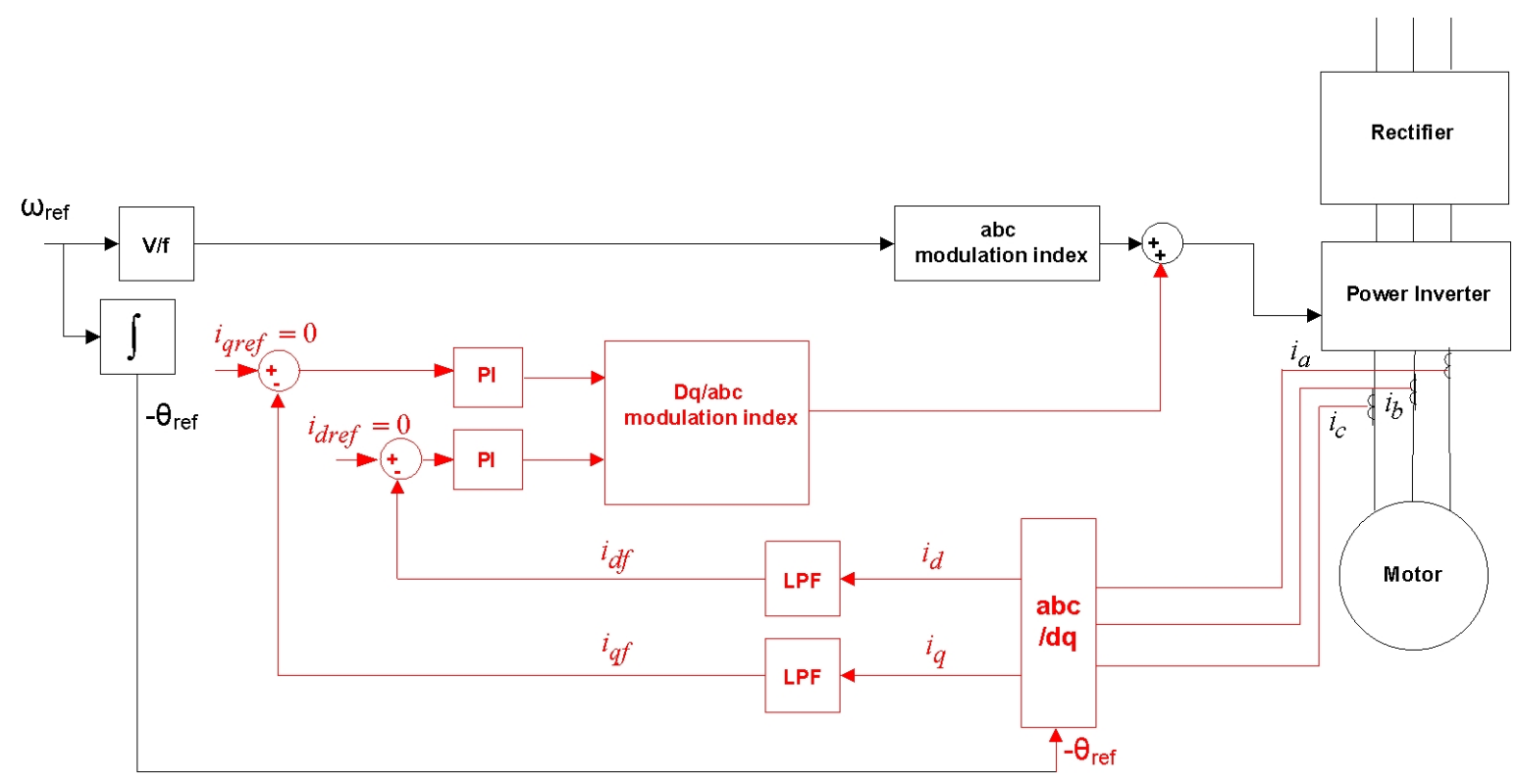

Fig. 2. A functional block diagram for an open-loop scalar V/f control with the introduced compensation algorithm.

In (7), the first term represents the forward component of the stator MMF while the second term represents the backward component of that MMF. Consequently, the backward component of the stator MMF can be forced to near zero by forcing the backward component of the stator current space-vector to near zero. Also, the three-phase line currents appearing on the side of the drive are thus rendered balanced with an amplitude value of each equal to the line currents under normal operation. This means that modifications in the power structure of the drive are not required. A simplified block diagram that describes the algorithms introduced here is depicted in Fig. 2.

\section{B. An insight into the structure of the introduced controller}

In any conventional constant (V/f) scalar control, the ratio between the voltage and the frequency of the reference signal fed to the modulator is kept constant, [22]. In addition to this conventional reference signal, the three-phase line currents are measured and transferred to a synchronous reference frame rotating backward in a clockwise direction $(\mathrm{CW})$ at a speed equal to the synchronous speed. The angle, $\theta_{\text {ref }}$, see Fig.2, used in the transformation is the result of the integration of the reference speed in electrical $\mathrm{rad} / \mathrm{sec}$, and it is generated internally in the controller. In this frame of reference, the backward $(\mathrm{CW})$ component of the stator current space-vector appears as a dc value in both the d-axis and the q-axis, while the forward Counter Clock Wise (CCW) component of the stator current space-vector appears as an ac component with a frequency equal to double the line frequency. This ac component is filtered through a low pass filter, while the dc components in the d-axis, $i_{d f}$, and in the q-axis, $i_{q f}$, are processed through two PI controllers to drive these components to zero.

At normal operation, for a balanced machine, the backward component of the stator current space-vector is very small or negligible. In this case, the dc component of the stator current space-vector in the synchronous CW frame of reference is almost zero. Consequently, the controller output will be negligible. Thus, although the introduced compensation algorithm is activated during a system's normal and faulty operation, the controller output is almost negligible or equal to zero only under normal operation.Upon the failure of a third phase of the motor winding, the backward component of the stator current space-vector will have a significant value. This backward component will appear as a dc component in a CW synchronously rotating reference frame. Therefore, the introduced controller will act to force this dc component to zero. The controller output is then added to the main reference signal normally generated in a conventional constant (V/f) scalar control system. The resultant summation is then fed to the modulator to generate the appropriate switching pattern. Forcing the backward component of the stator current spacevector to zero results in a balanced three-phase set of line currents with equal magnitudes and inter-phase shift angles of $120^{\circ} \mathrm{e}$. Meanwhile, the remaining two active phase currents are rendered with equal magnitudes and a phase shift angle of $60^{\circ} \mathrm{e}$, which leads to only CCW rotating MMF component, recall (4). This can be explained as a result of the nature of a Delta-connected winding, in which the end (finish) of each phase is connected to the beginning (start) of the other, with phase-c deactivated, see Fig. 1. That is the corresponding active two-phase currents of phase-a and phase-b in a stator winding with open-Delta, are equal to each other in magnitude with a phase shift equal to $60^{\circ} \mathrm{e}$ between each other. Hence, the overall result is a set of motor terminal line currents, $i_{A}, i_{B}$, and $i_{C}$, that are balanced with a sequential phase shift of $120^{\circ} \mathrm{e}$ which results-in a balanced positive sequence set of three phase currents. This is because of the fact that, with reference to Fig.1, one can state the following; $i_{A}=i_{b^{-}}$ $i_{a}, i_{B}=-i_{b}$, and $i_{C}=i_{a}$ (in other words, $i_{a}=i_{C}, i_{b}=-i_{B}$, and $\left.i_{c}=0\right)$. The relationship between the motor line current phasors $\bar{I}_{A}, \bar{I}_{B}, \bar{I}_{C}$ and phase current phasors $\bar{I}_{a}, \bar{I}_{b}, \bar{I}_{c}$ for the two-phase 
open-Delta mode of operation is illustrated in the phasor diagram of Fig. 3

\section{Controller Design}

The controller design specifications are: steady-state error $<1 \%$, overshoot $<5 \%$, and the closed-loop system should have a bandwidth of $5 \mathrm{~Hz}(31.4 \mathrm{rad} / \mathrm{sec})$. This is to suppress disturbances which are mainly originating from the ac ripples resulting from the existence of the forward component "rotating CCW" of the stator current space-vector in the CW synchronously rotating frame of reference utilized in this controller. The motor transfer function in the continuous timedomain can be defined from the motor transient impedance as follows, [22]:

$$
G(s)=\frac{1}{\left(R_{s}+R_{r}\right)+\left(L_{s}+L_{r}\right) s}
$$

where, Rs is the equivalent stator resistance per phase, Ls is the equivalent stator leakage inductances per phase, $\mathrm{Rr}$ is the rotor equivalent resistance per phase, and $\mathrm{Lr}$ is the equivalent rotor leakage inductance per phase, all referred to the stator side. Meanwhile, the PI-controller transfer function is, $\mathrm{C}(\mathrm{s})=\mathrm{Kp}+$ $(\mathrm{Ki} / \mathrm{s})$, also in the continuous time-domain. The inverter is represented by a gain of $(\mathrm{Vdc} / \sqrt{2})$ for a PWM space vector modulation technique. It is required to calculate the values of the gains $\mathrm{Kp}$ and $\mathrm{Ki}$ that render the closed-loop system response conforming to the same design specifications given above. The simplified current control loop in the $\mathrm{CW}$ frame of reference for both the d-axis, and q-axis current components, in the continuous time-domain is shown in Fig.4. Notice that in this Figure, $\mathrm{R}=\mathrm{Rs}+\mathrm{Rr}$, and $\mathrm{L}=\mathrm{Ls}+\mathrm{Lr}$.

Again, it is required to drive the dc component in the $\mathrm{CW}$ frame of reference to zero. In other words, one should aim at driving the backward component of the stator current space-vector to zero, and at the same time reject (or render the controller insensitive to) the ac ripples resulting from the existence of the forward component of the stator current spacevector.

The system was discretized using approximated zero order hold method " $\mathrm{ZOH}$ ". The low pass filter is a first order low pass filter that has a unity dc gain, a zero at $\mathrm{z}=-1$, and a pole at $\mathrm{z}=0.9984$, in a discrete domain with a sampling time of $100 \mu$ sec. This design yields an over damped filter response with a cut-off frequency that is equal to $2.5 \mathrm{~Hz}$. The openloop and the closed-loop Bode plots are depicted in Fig.5a and Fig. $5 \mathrm{~b}$ for controller gain values, $\mathrm{Kp}=0.01$ and $\mathrm{Ki}=0.1$, which yielded the required design performance. It can be noticed from the system Bode-plot closed-loop response that the cut-off frequency of the closed-loop system is $5 \mathrm{~Hz}(31.46$ $\mathrm{rad} / \mathrm{sec}$ ), which guarantees high degree of rejection of the ac ripples. On the other hand, it can be noticed that the closedloop system has a steady state error less than $1 \%, 50 \mathrm{~dB}$ gain margin, and 70 degree phase margin. This controller design is valid only for applications where the inverter supply frequency is greater than $5 \mathrm{~Hz}$ "which corresponds to ac ripples in the CW synchronous frame greater than $10 \mathrm{~Hz}$ ". In general, the cut-off frequency of the closed-loop system should be less than twice the supply frequency. Otherwise,

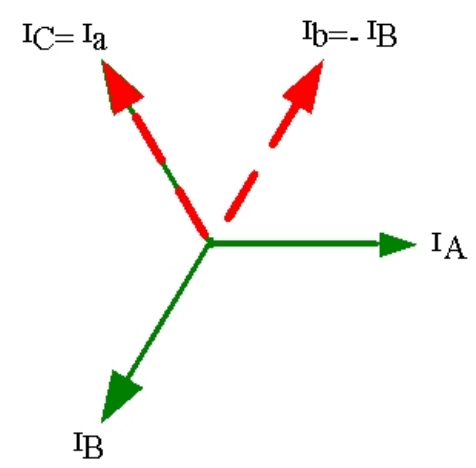

Fig. 3. Phasor diagram of motor phase and line currents at two-phase openDelta mode of operation (reference to Fig. 1).

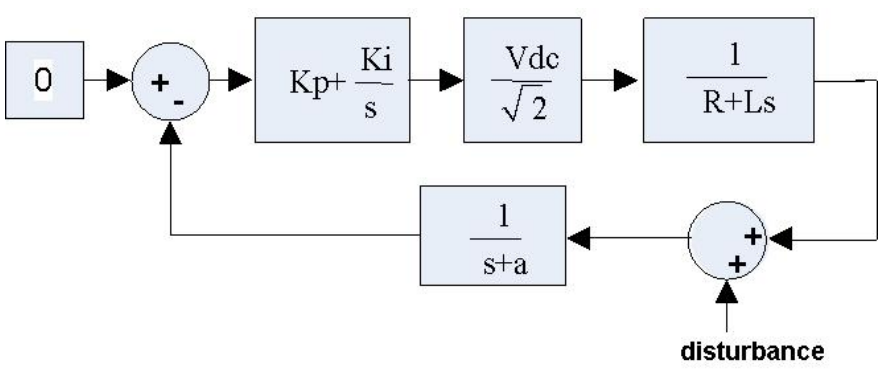

Fig. 4. Simplified current control loop in the CW frame of reference.

the ac ripples will propagate throughout the control system and will be amplified, which might cause unstable operation. The low pass filters in the current control loop for both the $\mathrm{d}$-axis and the q-axis current components shown in Fig.2 can be replaced by an adaptive notch filter, [23], that is tuned to double the operating frequency of the inverter. This is in order to obtain a faster transient response. However, this adaptive filter will increase the complexity of the control system and consequently increase the required processing power. Consequently, it was not implemented at this stage of the research.

\section{Simulation Models}

The simulation work was carried out using two different models. The first is a lumped-parameter motor-drive model, entirely implemented in MATLAB "Simulink toolbox and Simpowersystem toolbox." The second is a Time-Stepping Finite Element (TSFE) based motor-drive model that is implemented in MATLAB Simulink toolbox linked to a TSFE commercial software, namely, MAGSOFT/Flux2D. The details of each model are given below.

\section{A. An insight into the first simulation model MAT- LAB/Simulink}

The first model consists of a time-domain simulator that includes the system controller, the drive including the transistor switching effects, and the lumped parameter model of the case-study 5-hp motor. The motor is modeled here using the d-q stationary reference frame, in which saturation and effects 


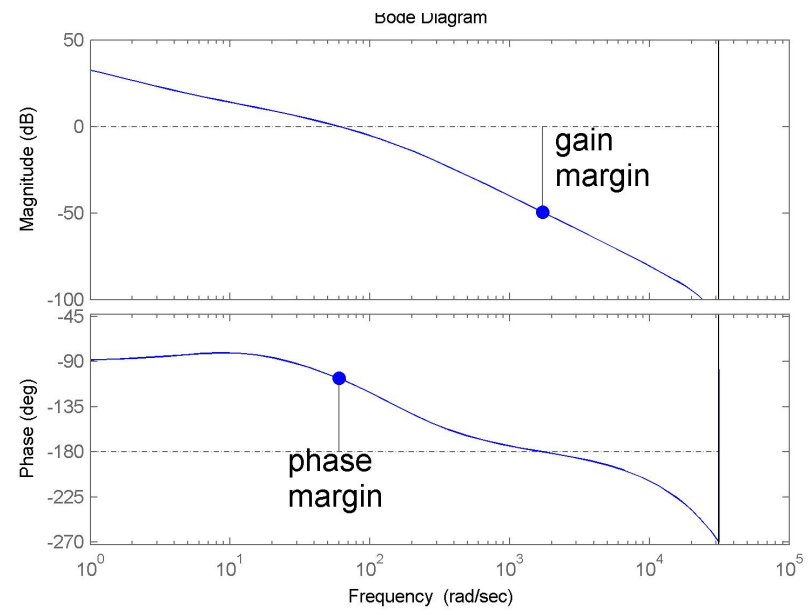

(a) Open loop response.

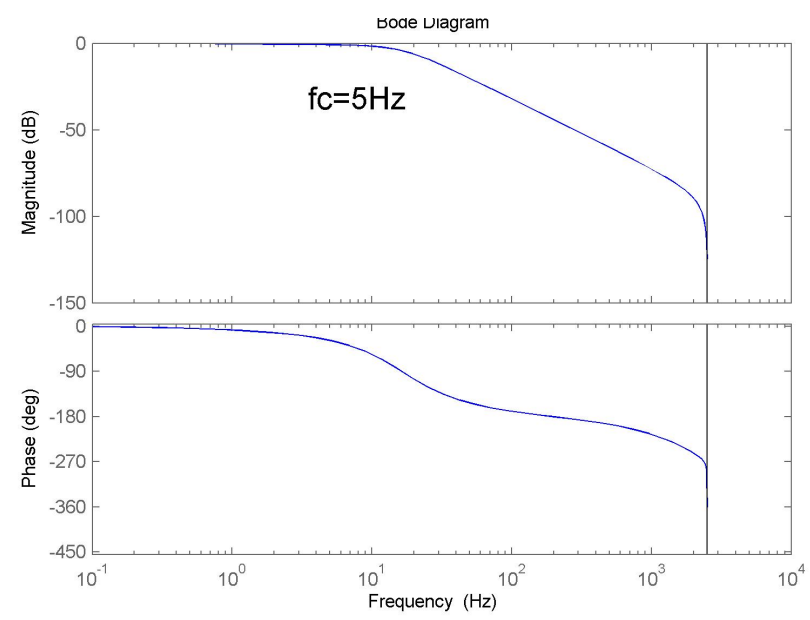

(b) Closed loop response.

Fig. 5. Bode plot responses for the current control loop " $K_{p}=0.01 \& K_{i}=0.1$ ".

of space harmonics higher than the fundamental airgap flux component are neglected, [22].

The time-step sample of this simulation model was chosen to be $1 \mu \mathrm{Sec}$, while the controller sampling time was chosen to be $100 \mu \mathrm{sec}$ to replicate the actual implementation in the DSP chip used in the drive associated with this experimental work.

\section{B. An insight into the second simulation model} MATLAB/Simulink-MAGSOFT/Flux2D

The second model consists of a time-domain simulator that includes the system's controller model implemented in MATLAB/Simulink toolbox. This model is linked to a detailed TSFE "MAGSOFT/Flux2D" software representation of the case-study motor, which includes the effects of MMF space harmonics (winding layouts), and magnetic circuit configuration, as well as magnetic nonlinearities due to saturation. Meanwhile, electric transients due to the power electronic switching of the transistors are not accounted for in this model, because the controllers' signals are assumed to operate two idealized controlled voltage sources feeding lines (AB) and $(\mathrm{BC})$ at the terminal of the motor. Only, the inverter gain for

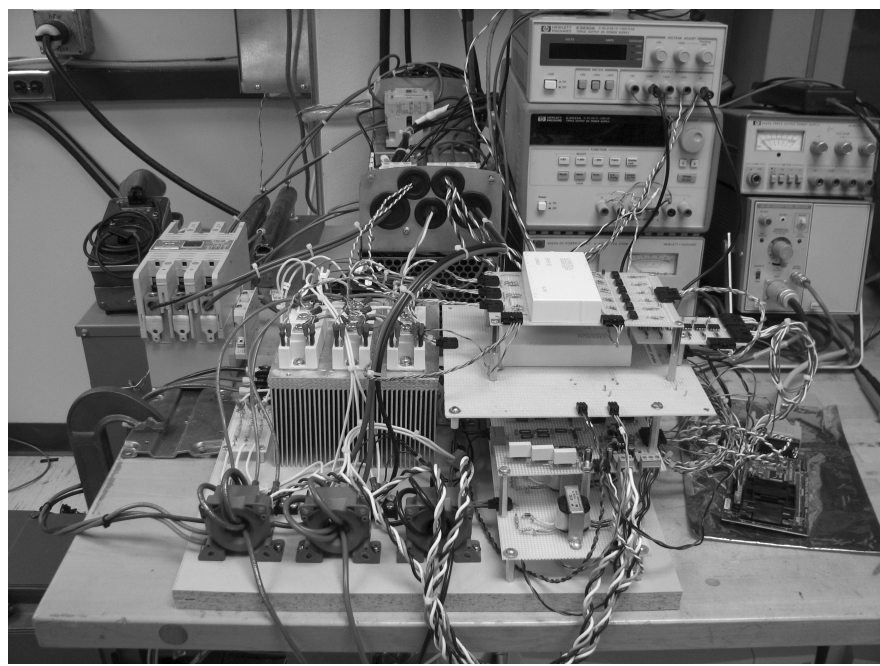

Fig. 6. Power converter utilized in the experimental testing.

the PWM space vector is needed where this gain is equal to $(\mathrm{Vdc} / \sqrt{2})$, [22], which was utilized in both the simulation and the experimental work. In this model, the calculated voltage is passed to the TSFE motor model, and the output currents are passed back from the TSFE software to the controller implemented in the Simulink environment for each time step.

In addition to the advantage of including MMF space harmonics and saturation effects in this model, several magnetic quantities are also available such as airgap flux densities and nodal magnetic vector potentials. Knowledge of these magnetic quantities is highly desirable to thoroughly analyze the machine performance. The case-study motor is a six-pole induction motor, which was designed such that it can be configured either as a six-phase or as three-phase induction motor, with the stator connected either as Wye or Delta. The stator consists of 36 stator slots and 45 rotor bars with closed slots. These design particulars implied the existence of the third, fifth and seventh harmonics in the phase currents, and consequently fifth and seventh harmonics in the line currents. The total harmonic distortion "THD" for the line currents is $1.6 \%$ and the THD of the phase currents is $3 \%$. A detailed analysis of this case-study motor with its design procedure was included in [24].

\section{The Motor-Drive Experimental SeT-Up}

In order to examine the performance of the introduced technique discussed earlier, the motor-drive system was simulated and experimentally tested at several operating conditions. The power structure of a commercial drive was interfaced to a DSP board "ezdsp F2812" in which the DSP chip "TMS320F2812" is the main processor that hosted the algorithms introduced earlier in this paper. The currents' sampling rate was set to $10 \mathrm{KHz}$. This new control algorithm was executed through an "interrupt service routine" which was periodically called every $100 \mu \mathrm{sec}$. The carrier/switching frequency was set to $10 \mathrm{KHz}$. The power converter of the experimental set-up is depicted in Fig. 6. 


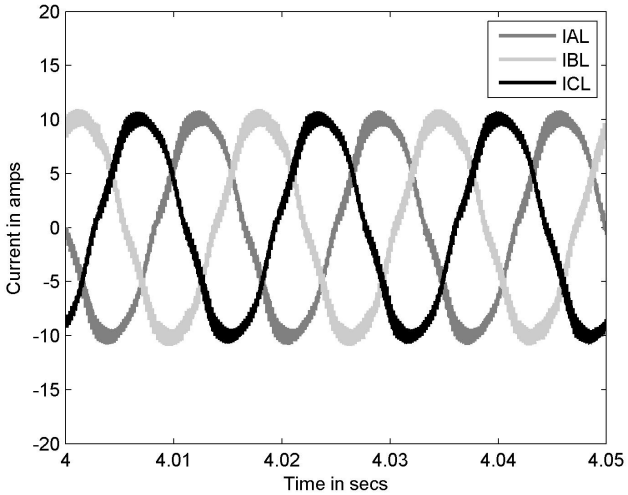

(a) Introduced controller deactivated.

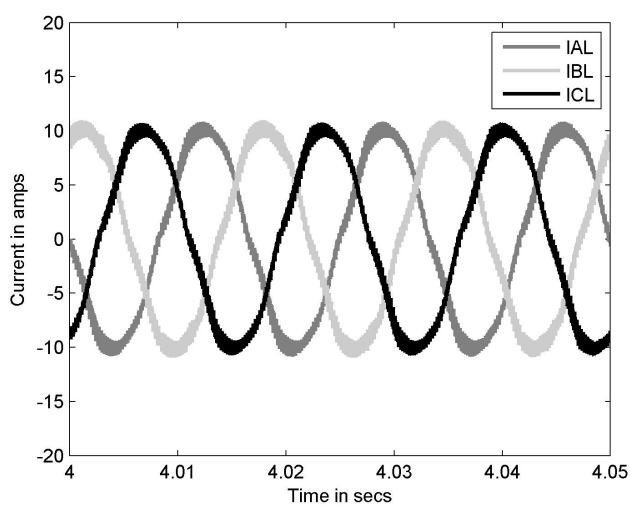

(b) Introduced controlled activated.

Fig. 7. Experimentally obtained line currents, open-loop, healthy three-phase operation, $60 \mathrm{~Hz}$.

\section{Simulation AND VALidating Experimental RESULTS- ANAYLASIS AND DisCUSSION}

\section{A. Experimental validation for the three-phase "healthy"} mode of operation

The motor-drive system was run under a healthy "threephase" mode of operation at half load operating condition, when the introduced controller was deactivated, and when the introduced controller was activated. The line current waveforms obtained from experimental results are depicted in Fig. 7(a) for the case when the introduced controller was deactivated and in Fig. 7(b) when the introduced controller was activated. In addition, the output torque profiles obtained from a torque transducer that is mechanically coupled to the motor and the dynamometer shaft, in both cases when the introduced controller was deactivated, and when the introduced controller was activated, are depicted in Fig. 8(a) and Fig. 8(b), respectively while their associated spectra are shown in Fig. 8(c). It can be noticed that the line current waveforms and the output torque profiles are almost identical for both of the two cases when the introduced controller was activated and when the introduced controller was deactivated. These experimental results confirm and validate the earlier discussion in this paper, which showed that the introduced controller does not have any significant effect that adversely affects system performance under healthy operating conditions.

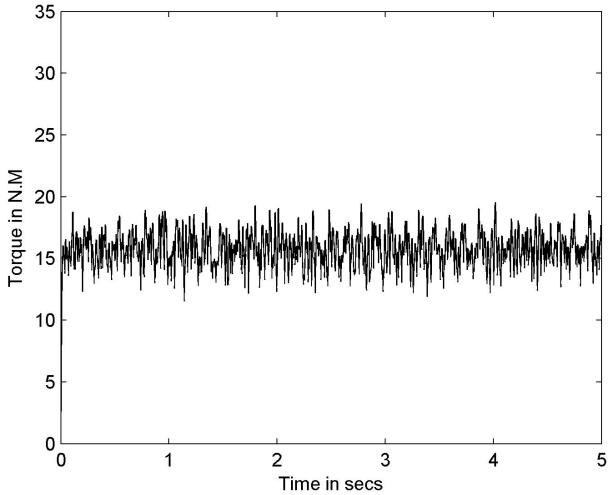

(a) Time domain waveform "introduced controller deactivated".

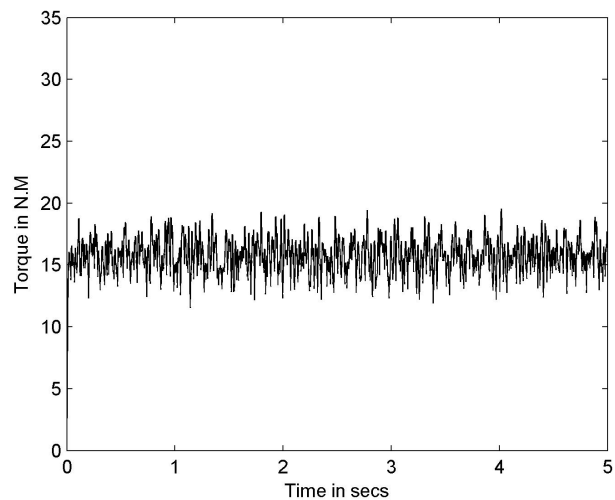

(b) Time domain waveform "introduced controller activated".

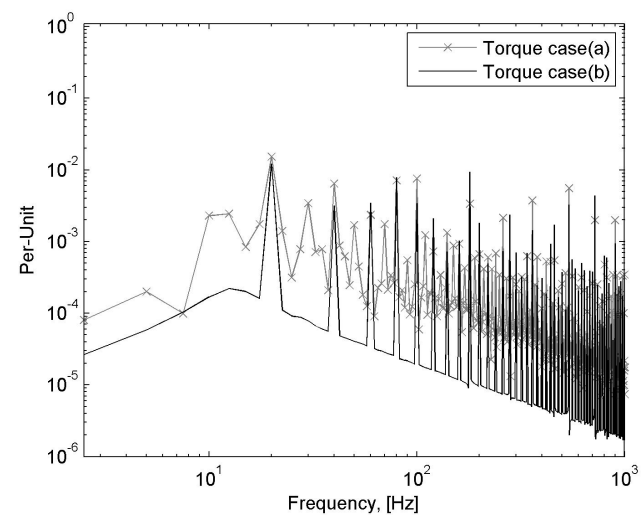

(c) Torque spectra: Case (a) The introduced controller deactivated, Case (b) The introduced control activated.

Fig. 8. Experimentally obtained Output torque $60 \mathrm{~Hz}$.

\section{B. Simulation and experimental results for the two-phase open-Delta mode of operation}

The results presented in Fig. 9 through Fig. 24 document the performance of the motor-drive system, when the newly introduced controller was deactivated, and when this controller was activated for the open-Delta two-phase mode of operation of the case-study motor used in this investigation.

The motor line current waveforms obtained from the simulation results of the Simulink/Simpowersystem model for the case of the two-phase open-Delta mode of operation of this motor when the new controller was deactivated are depicted 


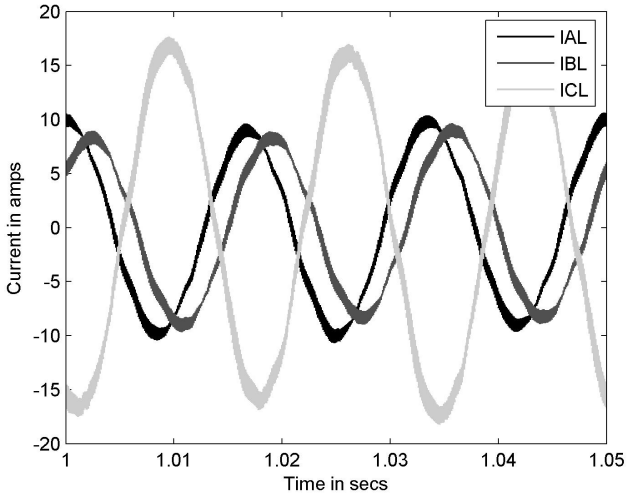

Fig. 9. Line currents, open-loop, the introduced controller deactivated under faulty two-phase open-Delta operation, $60 \mathrm{~Hz}$ "Simulink/Simpowersystem model".

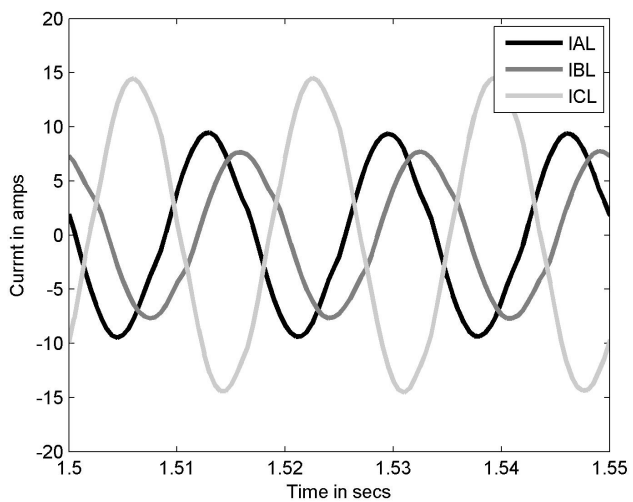

Fig. 10. Line currents, open-loop, the introduced controller deactivated, faulty two-phase open-Delta operation. 60Hz. "Coupled Simulink/Flux2D model".

in Fig. 9. It can be noticed that these currents are highly unbalanced with a significant negative sequence component.

C. Effects of space harmonics on the motor performance and motor line currents under two-phase open-Delta mode of operation

The results obtained from the time-stepping Simulink/Flux2D model show the appearance of a third harmonic current component in the machine line current waveforms when the machine is running under open-Delta two-phase mode of operation as given in the results of Fig. 10, see reference [25] for more details. This third harmonic component is mainly caused by the space harmonics of the stator MMF and its associated flux distribution waveform. In the healthy case, it appears only in the phase currents and not in the line currents because of the phase-to-line current cancellation effect in a Delta configuration. It should also be pointed out that the existence of this third harmonic component in the phase currents for the healthy case causes only circulating current in the Delta-connected motor phase windings, and does not produce torque pulsations since the resultant flux due to this third harmonic component is inherently equal to zero. Meanwhile, the third harmonic component in the motor phase winding currents will produce a resultant airgap flux in the case of the motor's two-phase open-Delta mode of operation, which consequently produces

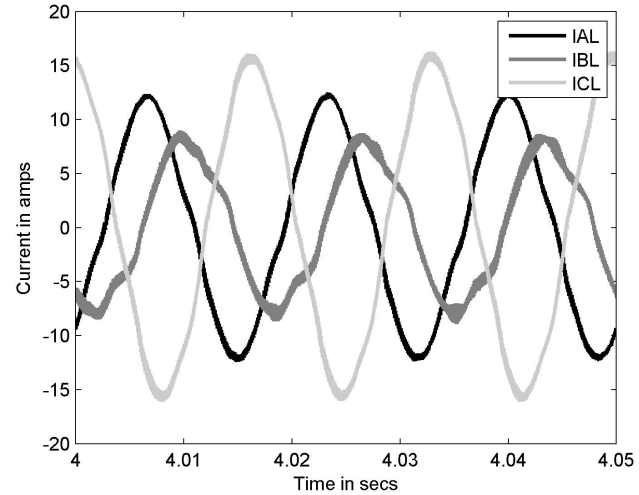

Fig. 11. Experimentally obtained line currents, open-loop, the introduced controller deactivated, two-phase open-Delta operation, $60 \mathrm{~Hz}$.

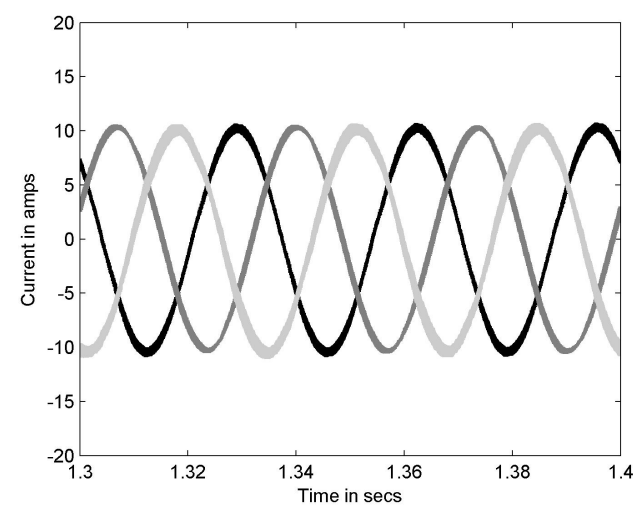

Fig. 12. Line currents, open-loop, the introduced controller activated, twophase open-Delta operation, $60 \mathrm{~Hz}$. "Simulink/Simpowersystem model".

torque ripples at double the line frequency due to the interaction between the fundamental forward rotating $(\mathrm{CCW})$ rotor MMF, and the resulting MMF component of the stator which is rotating forward $(\mathrm{CCW})$ at three times the synchronous speed. Also, the interaction between this stator MMF component and the induced backward (CW) MMF component of the rotor will produce torque pulsations at four times the fundamental frequency.

In addition to the undesired torque pulsations resulting from the unbalanced operation of the machine, this current unbalance significantly reduces the expected lifetime of the dc link capacitor, and may eventually cause a premature failure of the drive, [19], [20]. Meanwhile, the line current waveforms obtained from the experimental test set-up for the same casestudy motor-drive system are depicted in Fig. 11. It can be noticed that the line current waveforms obtained from the experimental test set-up are in better agreement with the corresponding waveforms obtained from the TSFE Coupled Simulink/ Flux2D model as compared to the simulation results of Simulink/Simpowersystem model. This is to be expected because of the rigorous account of magnetic circuit saturation, configuration and winding-layout effects naturally included in this Simulink/Flux2D modeling approach. 


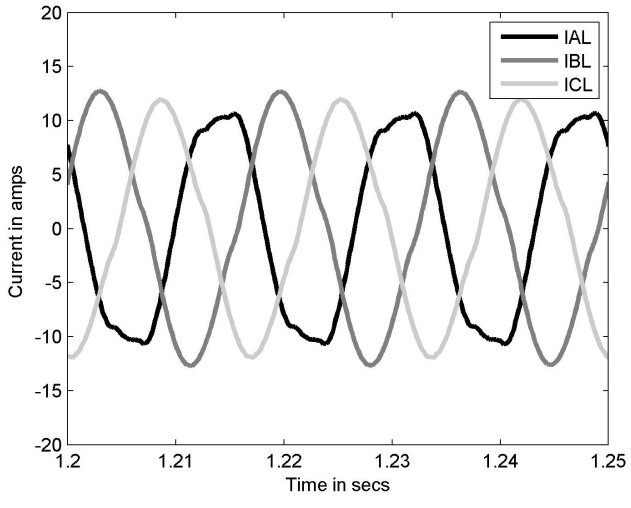

Fig. 13. Line currents, open-loop, the introduced controller activated, twophase open-Delta operation, $60 \mathrm{~Hz}$ "Coupled Simulink/Flux2D model".

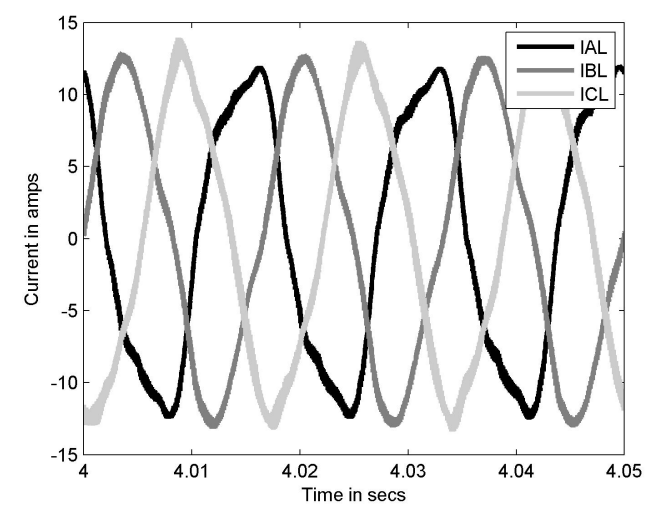

Fig. 14. Experimentally obtained line currents, open-loop, when the introduced controller was activated, two-phase open-Delta operation, $60 \mathrm{~Hz}$.

\section{Effect of the introduced control strategy on the unbalance and the negative sequence component in the motor line cur- rents}

The effectiveness of this newly introduced controller can be verified through comparing the unbalanced line-current waveforms for the case of two-phase open-Delta operation, when the newly introduced controller was deactivated, see Fig. 9 , and the balanced line-current waveforms for the case of two-phase open-Delta operation, when this newly introduced controller was activated, see Fig. 12. These figures show that this controller has diminished the magnitude of the negative sequence component in the line currents, which significantly improves the quality of the output torque of the machine as will be demonstrated later-on in this paper. The corresponding simulation results for the same set of cases using the TSFE Coupled Simulink/Flux2D are depicted in Fig. 10, when the controller was deactivated, as well as Fig. 13, when the controller was activated. Again, the effectiveness of this newly introduced controller can also be verified through examination of the unbalance in the line currents depicted in Fig. 10 when this controller was deactivated in comparison to the almost balanced set of line currents in Fig. 13 when this controller was activated. It should be pointed out that this controller compensates only for the unbalance in the fundamental components of the motor currents but not for the harmonics in the motor winding currents. The experimentally obtained line current waveforms for the case of the two-phase open-Delta mode of operation, when this controller was deactivated are depicted in Fig. 11. Meanwhile, the waveforms for the case when this controller was activated are depicted in Fig.14. Again, the effectiveness of this controller in balancing the line currents is self-evident upon comparison of the waveforms in Fig. 11 to the waveforms of Fig. 14. It can be noticed that these experimental results are in close agreement with the simulation results obtained using TSFE Coupled Simulink/Flux2D.

The increased distortion in the waveforms of the line currents obtained from simulink/Flux2D model as depicted in Fig. 13, and the corresponding experimental results depicted in Fig. 14, when compared to the corresponding results obtained from the Simulink/simpowersystem model depicted in Fig. 12, show that this distortion in the line currents is mainly due to the space harmonics associated with the machine's winding design, and the corresponding magnetic circuit. This is because the Simulink/simpowersystem is based on a simplified d-q motor model in which a sinusoidal MMF in the airgap is inherently assumed, and magnetic circuit saturation effects are not taken into account; see reference [22] for more details.

The transient performance of the newly introduced controller was also experimentally examined through monitoring the magnitude of the negative sequence component of the line currents which is depicted in Fig.15. It can be noticed in this figure that there is a sudden increase in the magnitude of the negative sequence component magnitude of the line currents at the instant that one of the phases was disconnected. Nevertheless, this controller was able to reduce the magnitude of the negative sequence component of the line currents to a value close to zero within a period of approximately 2 seconds of the occurrence of the fault, see Fig.1 5.

\section{E. Effect of the introduced control strategy on the motor output torque}

The effect of the compensation controller on the motor output torque can be verified by examining the output torque profiles obtained from the Simulink/Simpowersystem simulation, when this controller was deactivated, case (a), versus case (b) when the controller was activated, both of which are shown in Fig. 16(a) and their associated spectra are shown in Fig. 16(b). Significant torque ripples of $192 \%$ peak-topeak "96\% peak-to-average" of the average developed torque can be observed for the case (a) of the two-phase openDelta mode of operation, when the controller was deactivated. It can also be noticed from the output torque waveforms of Fig.16 (a) and Fig. 16(b) that this harmonic is highly diminished when the controller was activated in which only approximately $6 \%$ peak to peak of the average developed torque can be observed, see "case (b)" of Fig. 16(a) and Fig. 16(b). Meanwhile, the simulation results for the same two cases obtained from the TSFE Coupled Simulink/Flux2D model are depicted in Fig. 17(a) while their associated spectra are shown in Fig. 17(b). Examining the results obtained from the Simulink/Simpowersystem model and the TSFE Coupled Simulink/ Flux2D model lead to two observations. The first observation is that the torque ripples obtained from the TSFE Coupled Simulink/Flux2D model for the case of the twophase open-Delta mode of operation, when the controller 


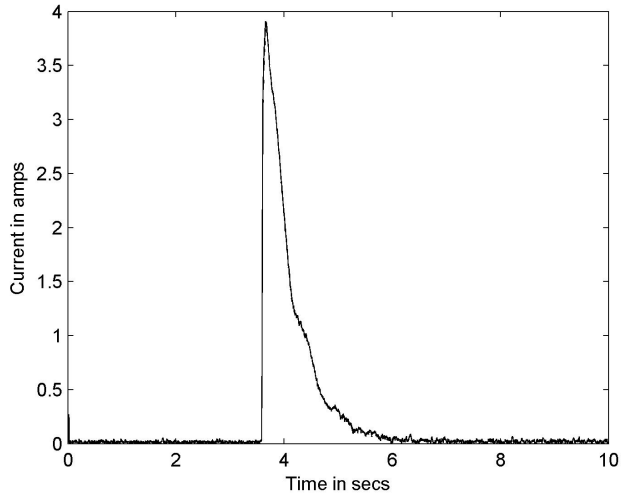

Fig. 15. Experimentally obtained negative sequence component of the line currents, transfer from three-phase mode to two-phase open-Delta mode when the introduced controller was activated, $60 \mathrm{~Hz}$.

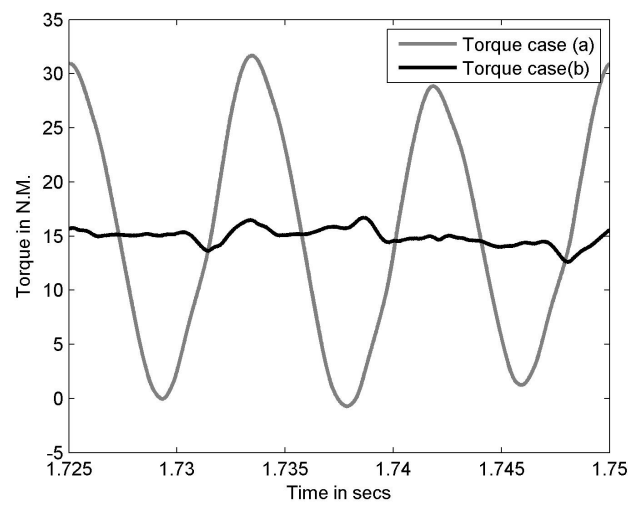

(a) Time domain waveforms.

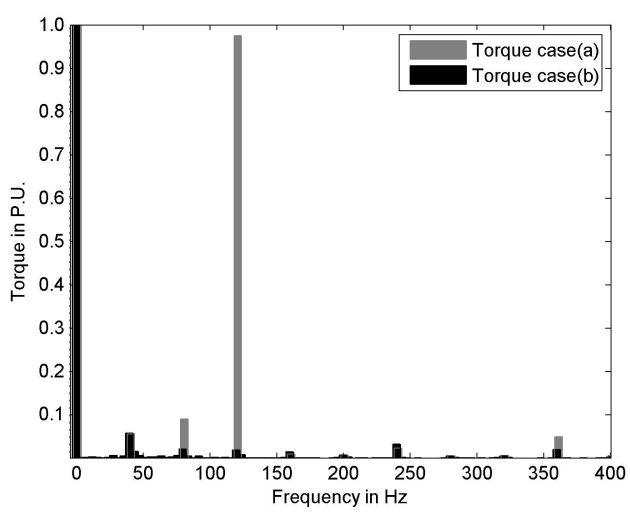

(b) Frequency spectra.

Fig. 16. Output torque, open-loop, $60 \mathrm{~Hz}$, two-phase open-Delta "Simulink/Simpowersystem model": Case (a) The introduced control deactivated. Case (b) The introduced control activated.

was deactivated, is less than the corresponding torque ripples obtained from the Simulink/Simpowersystem model.

It should be pointed out that the torque ripples obtained from Simulink/Simpowersystem in the case of the two-phase open-Delta mode of operation are due to the backward rotating (CW) MMF components, $M M F_{s c w}$ and $M M F_{r c w}$ resulting from the unbalance in the machine as described earlier in section II. On the other hand, in addition to the aforementioned torque ripples, the resultant torque obtained from the Coupled Simulink/Flux2D include torque ripples produced due to the

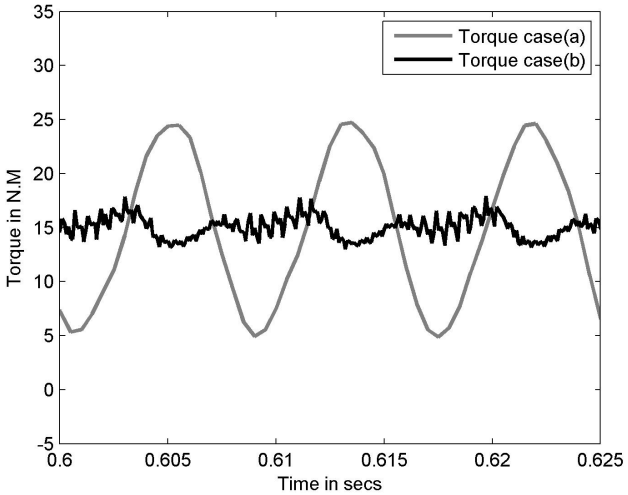

(a) Time domain waveforms.

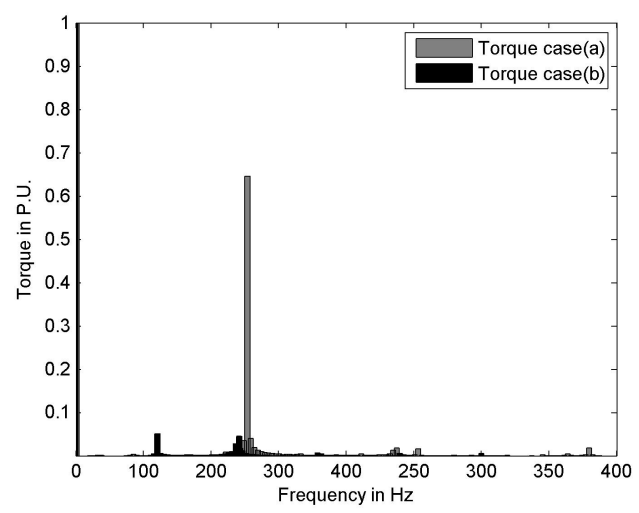

(b) Frequency spectra.

Fig. 17. Output torque, open-loop, 60Hz, two-phase open-Delta "Coupled Simulink/Flux2D" :Case (a) The introduced controller deactivated. Case (b) The introduced control activated.

interactions between the machine's MMF space harmonics described earlier in subsection $\mathrm{C}$. Thus, the resultant torque ripples may increase or decrease depending on the phase shift between these torque components. The second observation on the results obtained from Fig. 17(a) and Fig. 17(b) is that the torque ripple component that has double the line frequency has diminished from approximately $130 \%$ peak to peak " $65 \%$ peak to average" of the average developed torque when the compensation controller was deactivated, "case (a)" of Fig. 17(a) and Fig. 17(b), to approximately $10 \%$ peak to peak "5\% peak to average" of the average developed torque when this controller was activated, "case (b)" of Fig. 17(a) and Fig. 17 (b).

The torque profiles measured by the torque transducer in the experimental tests are depicted in Fig. 18(a) and their associated spectra are shown in Fig. 18(b) in which the measured torque signals were filtered through a low pass filter that has a cut-off frequency equals to $350 \mathrm{~Hz}$. A peak to peak torque ripples of approximately $95 \%$ peak to peak of the average developed torque can be observed when this controller was deactivated at steady-state condition as shown in case (a). Meanwhile, a peak to peak torque ripples of approximately $14 \%$ "7\% peak to average" of the average developed torque appeared when this controller was activated under steadystate which can be observed as shown in case (b). It can be observed that activating the controller significantly reduced 


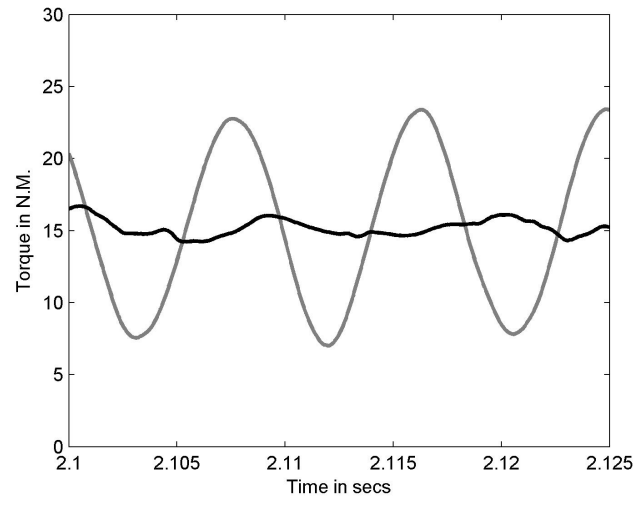

(a) Time domain waveforms.

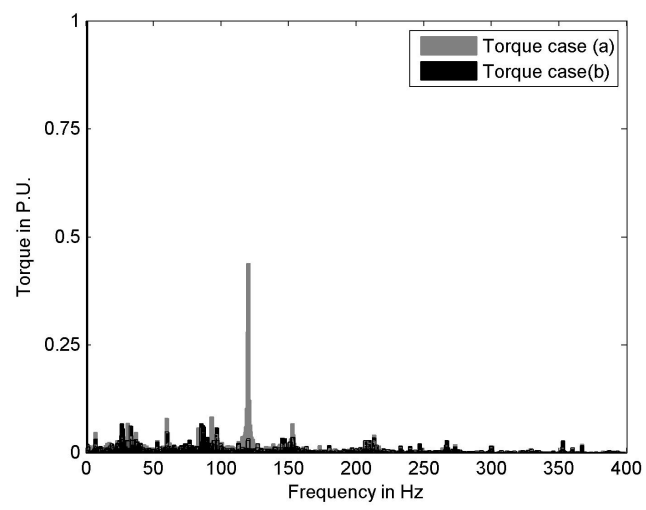

(b) Frequency spectra.

Fig. 18. Experimentally obtained output torque, open-loop , two-phase openDelta operation, 60Hz: Case (a) The introduced controller deactivated Case (b) The introduced control activated

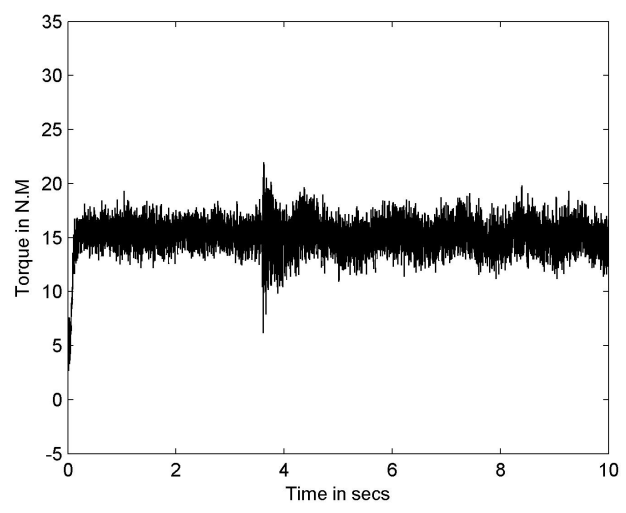

Fig. 19. Experimentally obtained output torque, open-loop, three-phase to two-phase open-Delta transient response when the introduced controller was "activated," $60 \mathrm{~Hz}$

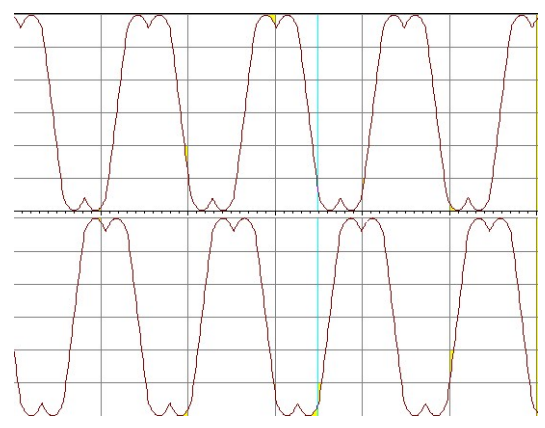

Fig. 20. DSP output modulating signals for gate drives of phase A and phase $\mathrm{C}$, open-loop $60 \mathrm{~Hz}$, two-phase open-Delta operation, the introduced controller deactivated, (Horizontal Scale 5ms/div, Vertical scale 0.2 P.U).

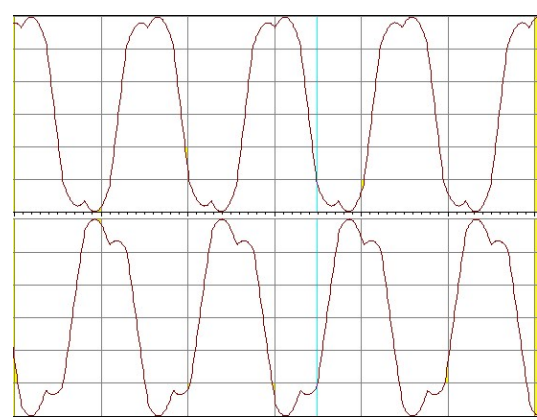

Fig. 21. Experimentally obtained DSP output modulating signals for gate drives of phase A and phase C, open-loop $60 \mathrm{~Hz}$, two-phase open-Delta operation, the introduced controller activated, (Horizontal Scale $5 \mathrm{~ms} / \mathrm{div}$, Vertical scale 0.2 P.U).

the torque ripples. Meanwhile, the torque profile at the instant of the transfer between the three-phase mode of operation to the two-phase open-Delta mode of operation is depicted in Fig. 19. This Figure demonstrates the efficacy of this fault mitigation method and associated quality of the new controller in preserving the motor's torque quality under faulty operating conditions, almost to the same degree of "goodness" as that of the healthy mode of operation.

\section{F. Results pertaining to the control electronics and machine magnetic quantities}

The previous discussion demonstrates the beneficial effects of the newly introduced controller on the motor current unbalances, and torque pulsations. Again, the main concept is that the controller is compensating for the unbalance in the machine through outputting a set of unbalanced voltages that render the resulting system line currents to be almost in balance, thus minimizing the stator's backward rotating (CW) MMF component. This is achieved through controlling the modulating signals. For instance, the modulating signals of the gate drivers of phases $\mathrm{A}$ and $\mathrm{C}$ while the controller was deactivated are depicted in Fig. 20, while the waveforms of Fig. 21 depict the same modulating signals in a period during which the controller was activated. A close comparison between these two figures, Fig. 20 and Fig. 21, reveals the effect of the compensation action of the controller on those modulating signals. The unbalance in the applied voltage also has a significant effect on the mid-airgap flux density waveform, and the machine's flux densities. The mid-airgap flux density waveform for the case of the two-phase openDelta mode of operation, when the controller was deactivated 


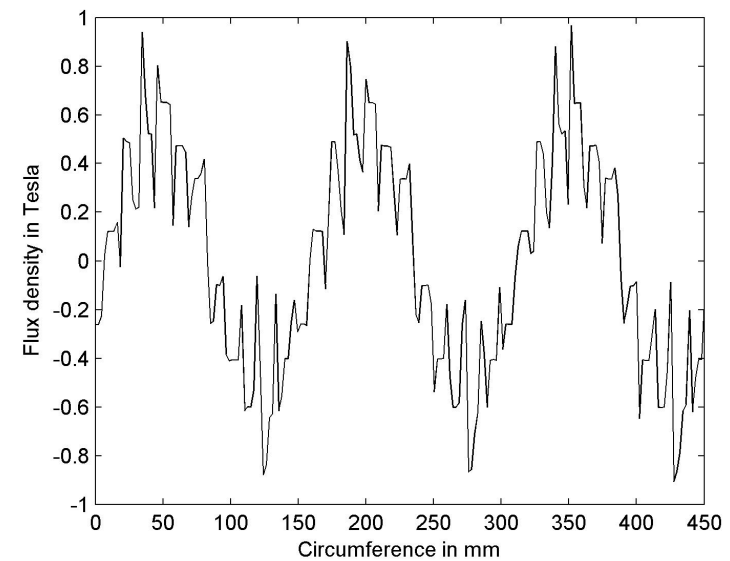

(a) Spatial waveform.

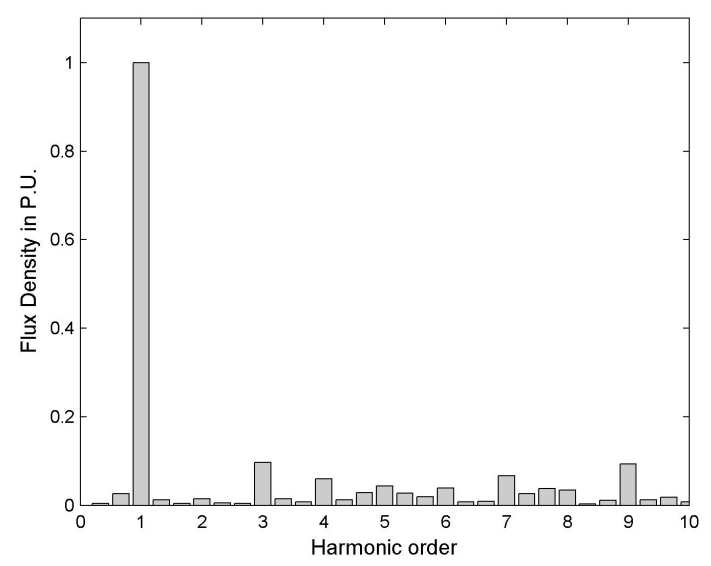

(b) Frequency spectrum.

Fig. 22. Airgap flux density, open-loop, when the introduced controller was deactivated, two-phase open-Delta operation, 60Hz, "Coupled Simulink / Flux2D”.

is shown in Fig. 22(a), while its corresponding spectrum is depicted in Fig. 22(b). Examining the spectrum of Fig. 22(b) shows the existence of the third order space harmonic in addition to the fifth and seventh order space harmonics as explained earlier. It is also important to highlight the fact that a third order time harmonic has also been observed in the motor line currents for the same case as explained earlier. Meanwhile, the mid-airgap flux density waveform for the case of the two-phase open-Delta mode of operation, when the introduced controller was activated is shown in Fig. 23(a), with its associated spectrum shown in Fig. 23(b), in which a significant increase in its third order and ninth order space harmonics can be observed. These waveforms are given at a random time instant and a corresponding random rotor position. It should be pointed out that the compensation action of the controller renders a set of unbalanced voltages applied to the motor terminals in order to obtain a set of nearly balanced line currents. This voltage unbalance results in a distortion in the mid-airgap flux density waveform with a high percentage of the third and ninth order space harmonics, as just discussed and explained above.

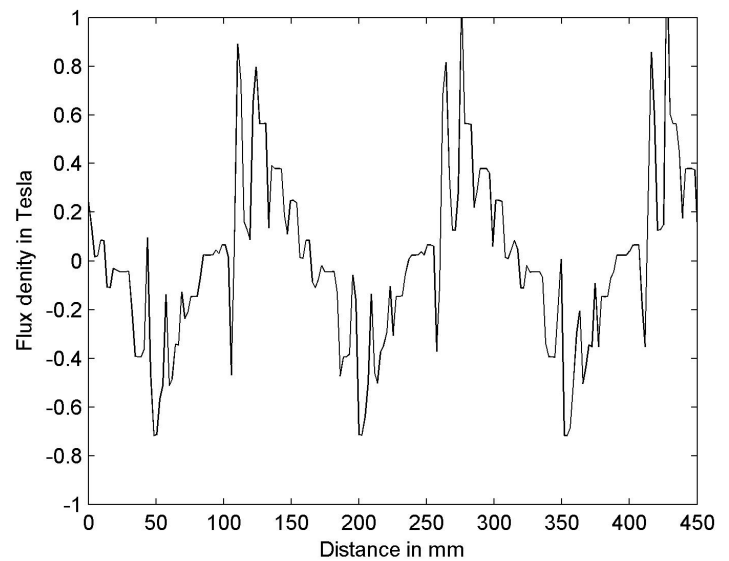

(a) Spatial waveform.

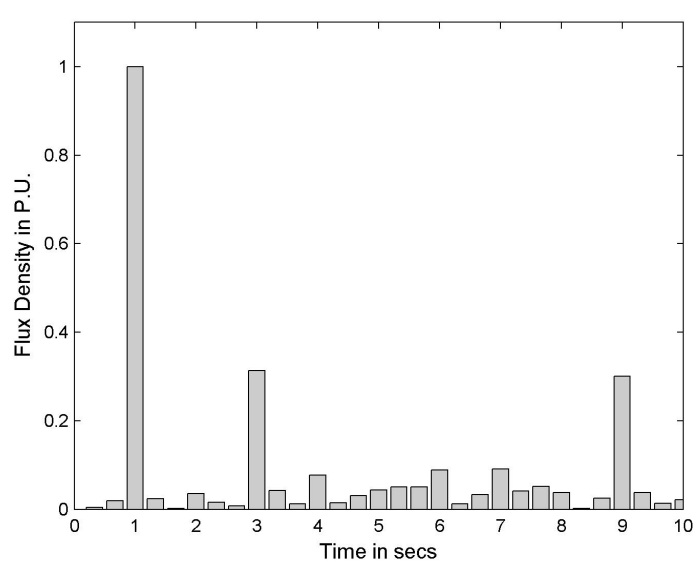

(b) Frequency spectrum.

Fig. 23. Airgap flux density at a given time instant, open-loop, when the introduced controller was activated, two-phase open-Delta operation, $60 \mathrm{~Hz}$, "Coupled Simulink/ Flux2D".

\section{CONCLUSIONS}

The conceptual and theoretical background as well as the validating experimental results of a new control technique that enables the two-phase mode of operation of an open-loop motor-drive system, with a motor's stator winding connected in a Delta configuration was presented in this paper. This technique takes advantage of the additional degree of freedom inherently provided in a Delta-connected polyphase stator winding in which the current in the two remaining active phases can be controlled independently. In this paper, it was shown that one of the advantages of the open-Delta configuration is that the phase currents in the remaining active phases can be controlled independently such that an only forward rotating component (CCW) MMF can be produced while keeping nearly balanced line currents with only a positive sequence component

The theoretical analysis introduced in this paper is also valid for permanent magnet ac machines with Delta-connected stator windings. The introduced control topology does not require oversizing of the drive. However, the machine has to be oversized if it is required to deliver the rated output power under a faulty two phase open-Delta mode of oper- 
ation. It was also shown in this paper that the introduced controller can be activated at normal "three-phase" mode of operation without adversely affecting the drive's performance. Meanwhile, the introduced controller was able to significantly diminish unbalances in line currents, as well as diminish the torque pulsations resulting from the faulty "two-phase openDelta" mode of operation from levels of $192 \%-95 \%$ peak to peak of the average developed torque to levels of $10 \%-14 \%$ peak to peak of the average developed torque. The introduced technique was experimentally implemented and tested using a 5-hp motor-drive set-up. Again, the results obtained from the Simulation runs and the experimental testing demonstrated the efficacy of the introduced control topology in diminishing the torque pulsations at two-phase "open-Delta" mode of operation of Delta-connected induction motors, and its efficacy in diminishing the unbalances in their line currents.

\section{REFERENCES}

[1] R. J. Kerkman, G.L Skibinski, D.W. Schlegel "AC drives: year 2000 (Y2K) and beyond," Applied Power Electronics Conference and Exposition, pp. 28-39, 1999.

[2] T. Jahns, "Improved reliability in solid-state drives for large asynchronous ac machines by means of multiple-independent phase-drive units," IEEE Trans. Ind. Appl., Vol. 1A-16, No. 3, pp. 321-331, May/Jun. 1980.

[3] L. W. Langley and R. B. Bross, "Motor with redundant windings," US patent number 4,434,389, Feb. 1984.

[4] R. B. Sepe, Jr. Fahimi, B. Morrison, and C. Miller, "Fault tolerant operation of induction motor drives with automatic controller reconfiguration," IEEE Electric Machines and Drives Conference, pp.156-162, 2001.

[5] J. D. Heinzmann, J. B. Morrell, and J. M. Sachs, "Model based faultdetection in a motor drive," US patent number 7,091,724 B2, 2006.

[6] N. Ertugrul, W. Soong, G.Dostal, and D.Saxon, "Fault tolerant motor drive system with redundancy for critical applications," Power Electronics Specialists Conference, pp. 1457-1462, 2002.

[7] T. H. Liu, F. Jen-Ren, and T. A Lipo "A strategy for improving reliability of field-oriented controlled induction motor drives," IEEE Trans. Ind. Appl., , Vol. 29, No. 5, pp. 910-918, Sep./Oct. 1993.

[8] T. Elch-Heb and J. P. Hautier "Remedial strategy for inverter-induction machine system faults using two-phase operation," Power Electronics and Applications, pp. 151-156, Sep.1 993.

[9] F. Jen-Ren and T. A. Lipo, "Disturbance-free operation of a multiphase current-regulated motor drive with an opened phase," IEEE Trans. Ind. Appl., Vol. 30, No. 5, pp. 1267-1274, Sep./Oct. 1994.

[10] D. Kastha and B. K. Bose, "Fault mode single-phase operation of a variable frequency induction motor drive and improvement of pulsating torque characteristics," IEEE Trans. Ind. Electron., Vol. 41, No. 4, pp. 426-433, Aug. 1994.

[11] D. Kastha and B. K. Bose, "On-line search based pulsating torque compensation of a fault mode single-phase variable frequency induction motor drive," IEEE Trans. Ind. Appl., Vol. 30, No. 4, pp. 802-811, Jul./Aug. 1995.

[12] B. A Welchko, T. M. Jahns, and T. A. Lipo, "Short-circuit fault mitigation methods for interior PM synchronous machine drives using six-leg inverters," Power Electronics Specialists Conference, pp. 21332139, 2004

[13] B. A. Welchko, "IPM synchronous machine drive response to a singlephase open circuit fault," IEEE Trans. Power Electron., Vol. 17, No. 5, pp. 764-771, Sep. 2002.

[14] Y. Lee and T. G. Habetler "A stator turn fault tolerant strategy for induction motor drives in safety critical applications," Power Electronics Specialists Conference, pp. 1-7, 2006.

[15] J. Aguayo, A. Claudio, L. G. Vela, S. Lesceq, and A. Barraud, "Stator winding fault detection for an induction motor drive using actuator as sensor principle," Power Electronics Specialist Conference, pp. 13471351, 2003.

[16] R. M. Tallam, S.-B. Lee, G. C. Stone, G. B. Kliman, J. Yoo, T. G Habetler, R. G. and Harley, "A survey of methods for detection of statorrelated faults in induction machines," IEEE Trans. Ind. Appl., Vol. 43 , No. 4, pp. 920-933, Jul./Aug. 2007.
[17] C. Gerada, K. J. Bradley, M. Summer, and P. Wheeler, "Operating induction motor drives with turn-to-turn faults," IEEE International Conference on Electric Machines and Drives, pp. 770-776, May 2005.

[18] J. E. Timperley, " Root cause analysis of machine stator failures" Doble Engineering Strategies, www.doble.com, 2009.

[19] Y.-H. Kim, N.-J. Park, D.-S. Hyun, "Advanced synchronous reference frame controller for three-phase ups powering unbalanced and nonlinear loads," IEEE Power Electronics Specialists Conference, pp.1699-1704, Jun. 2005.

[20] A. V. Jouanne, P. Enjeti, and D. Lucas, "DSP control of high power UPS systems feeding nonlinear loads," in Proceedings of the American Control Conference, , pp. 495-499, Jun. 1995.

[21] P. Vas, "Sensoreless vector and direct torque control," Oxford science publications, Chap. 2, 1998.

[22] B. Bose, "Modern power electronics and AC drives," Prentice Hall PTR, Chap. 8, 2002.

[23] S. Haykin, "Adaptive filter theory", Prentice-Hall, Inc, fourth edition, Chap. 5, 2002.

[24] A. A. Kadaba, "Design and modeling of a reversible 3-phase to 6-phase induction motor for improved survivability under faulty conditions," M. S., Department of Electrical and Computer Engineering, Marquette University, May 2008.

[25] A. M. S.-Ahmed, "Control of PWM AC motor drive systems under faulty conditions," Ph.D. dissertation, Department of Electrical and Computer Engineering, Marquette University, Dec. 2009.

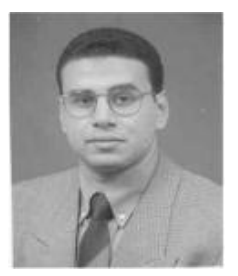

Ahmed Sayed-Ahmed (S'05-M'09) received the B.Sc and M.Sc degree in Electrical Engineering in 1998, and 2003 from Cairo University, Egypt. He received his Ph.D. in Electrical Engineering from Marquette University, WI, USA in 2009. From 1999 to 2005, he was working in Oil \& Gas industry where his last position was a senior electrical engineer. From 2006 to 2007, he was with Eaton Innovation center as a power electronics intern where he was working on control algorithms for hybrid power generation systems. From 2007 to 2008, he was a power electronics intern with Rockwell Automation Standard Drives Business, applied research group. He joined the same department in 2008, where he is currently a senior firmware/control engineer. His main research interests are embedded real-time control of power electronic devices as well as motor-drive systems. Dr. Sayed-Ahmed is a senior member of IEEE Power Electronics and IEEE Industry Application societies. He is also the vice chair of the Milwaukee IEEE power electronics chapter.

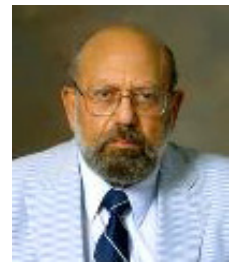

Nabeel A. O. Demerdash (M'65-SM'74-F'90-LF'09) received the B.Sc.E.E. degree (distinction with firstclass honors) from Cairo University, Cairo, Egypt, in 1964, and the M.S.E.E. and Ph.D. degrees from the University of Pittsburgh, Pittsburgh, PA, in 1967 and 1971, respectively. From 1968 to 1972, he was a Development Engineer with the Large Rotating Apparatus Development Engineering Department, Westinghouse Electric Corporation, East Pittsburgh, PA. From 1972 to 1983, he was an Assistant Professor, an Associate Professor, and a Professor in the Department of Electrical Engineering, Virginia Polytechnic Institute and State University, Blacksburg. From 1983 to 1994, he was a Professor in the Department of Electrical and Computer Engineering, Clarkson University, Potsdam, NY. Since 1994, he has been a Professor in the Department of Electrical and Computer Engineering, Marquette University, Milwaukee, WI, where he was the Department Chair from 1994 to 1997. $\mathrm{He}$ is the author or coauthor of more than 100 papers published in various IEEE Transactions. His current research interests include power electronic applications to electric machines and drives, electromechanical propulsion and actuation, computational electromagnetics in machines and drives, as well as fault diagnostics and modeling of harmonic effects in machine-power systems. Prof. Demerdash is a member of the Electric Machinery Committees of the IEEE Power Engineering Society (PES) and its various subcommittees, as well as the Electric Machines Committee of the Industry Application Society (IAS). He is listed in the Distinguished Lecturer Program of the PES and the Distinguished Speaker Program of the IEEE Industrial Electronics Society. $\mathrm{He}$ is the winner of the 1999 IEEE Nikola Tesla Technical Field Award. He is also the winner of two 1994 Working Group Awards from both the PES and its Electric Machinery Committee and a winner of two 1993 Prize Paper Awards from both the PES and its Electric Machinery Committee. He is a member of the American Society of Engineering Education, the Sigma Xi, and the Electromagnetics Academy 